\title{
UNL e IEM recebem o Terceiro Atelier Doutoral da Casa de Velázquez
}

André Luiz Bertoli

\section{(2) OpenEdition}

\section{Journals}

\section{Edição electrónica}

URL: http://journals.openedition.org/medievalista/531

DOI: 10.4000/medievalista.531

ISSN: $1646-740 \mathrm{X}$

\section{Editora}

Instituto de Estudos Medievais - FCSH-UNL

Refêrencia eletrónica

André Luiz Bertoli, « UNL e IEM recebem o Terceiro Atelier Doutoral da Casa de Velázquez », Medievalista [Online], 9 | 2011, posto online no dia 02 janeiro 2011, consultado o 15 setembro 2020 URL : http://journals.openedition.org/medievalista/531

\section{(c) (7) (8)}

Mediavalista está licenciado com uma Licença Creative Commons - Atribuição-NãoComercial 4.0 Internacional. 
Titulo: UNL e IEM recebem o Terceiro Atelier Doutoral da Casa de

Velázquez.

Autor(es): André Luiz Bertoli

Enquadramento Institucional: Membro do Instituto de Estudos Medievais (IEM) e do NEMED/UFPR (Núcleo de Estudos Mediterrânicos, Universidade Federal do Paraná, Brasil)

Contacto: andrelbertoli@gmail.com

Fonte: Medievalista [Em linha]. №9, (Dezembro 2010). Direc. José Mattoso. Lisboa: IEM.

Disponível em: http://www2.fcsh.unl.pt/iem/medievalista/

ISSN: $1646-740 \mathrm{X}$

\section{UNL e IEM recebem o Terceiro Atelier Doutoral da Casa de Velázquez}

André Luiz Bertoli

A Faculdade de Ciências Sociais e Humanas da Universidade Nova de Lisboa (FCSH/UNL) e o Instituto de Estudos Medievais (IEM) receberam a terceira edição do Atelier d'Études Médiévales Ibériques, realizado entre os dias 08 e 11 de Novembro de 2010. Promovido pela Casa de Velázquez sob coordenação científica do Professor Daniel Baloup e do Professor Bernardo Vasconcelos e Sousa, a edição 2010 do Atelier contou com a participação de doutores e doutorandos vinculados às seguintes 
instituições: Consejo Superior de Investigaciones Científicas (CSIC, Madrid), Universidad de Extremadura, Universidad de Valladolid, Universitat de València, École des Hautes Études Hispaniques et Ibériques (EHEHI, Casa de Velázquez), Université Paris I - Sorbonne, Université de Poitiers, Université Toulouse II, Universidade Nova de Lisboa (UNL), Universidade de Coimbra (UC) e Universidade Federal do Rio de Janeiro (UFRJ).

O Atelier de formação de investigadores deste ano, inserido num conjunto mais amplo de atividades científicas (colóquios, jornadas de estudo e seminários) organizadas pela Casa de Velázquez, teve como tema central os "Conflitos Armados e Violência Guerreira na Idade Média (Península Ibérica e Magrebe)". Com o objetivo de integrar os participantes das diferentes instituições num circuito internacional de formação e debate científico sobre a Idade Média, este evento proporcionou a todos a possibilidade de refletir sobre estudos que destacam a guerra e a violência medieval, sua organização, prática, agentes, fontes documentais e representações.

A dinâmica de trabalho ao longo da semana foi interessante, sendo dividida em três momentos distintos que ocorreram alternadamente: Conferências, Exposições e Trabalho em Grupos. Em seu conjunto, esta proposta de trabalho teve grande valor, pois levou em conta não só a colaboração que os conferencistas poderiam dar aos jovens investigadores, mas, sobretudo, propiciou uma troca de idéias, teorias, metodologias, propostas de novas questões e abordagens das fontes e, também, um espaço para sugestões, resultado de um diálogo mais aberto entre todos os participantes. Realizouse, ainda, uma visita guiada ao Arquivo Nacional Torre do Tombo (ANTT).

Dentre os conferencistas/formadores neste Atelier, estiveram presentes os Professores João Gouveia Monteiro (U. de Coimbra), Stéphane Boissellier (U. de Poitiers), Amaia Arizaleta (U. de Toulouse II), Daniel Baloup (EHEHI, Casa de Velázquez), Covadonga Valdaliso Casanova (U. de Valladolid), Jorge Saíz Serrano (U. de Valência) e Dominique Valérian (U. Paris I). Entre uma e outra conferência destes renomados pesquisadores, os recém doutores e doutorandos expuseram suas pesquisas dentro de três linhas temáticas definidas conforme os seus interesses de investigação. $\mathrm{O}$ primeiro tema era "Guerra e sociedade na Idade Média", da qual fizeram parte Fernando Arias Guillén (CSIC, Madrid), Salvador Ferrando Palomares (U. de Valência), Alexandre Giunta (U. de Toulouse II), Virginia Labrador (U. de Valladolid) e Carlos J. Rodríguez 
Casillas (U. de Extremadura). O segundo tema era "Marcas no espaço e vestígios materiais dos conflitos", na qual figuraram Erwan Le Balch (U. Paris I), Christophe Tropeau (U. de Poitiers) e Piero Fois (U. Paris I). Por fim, o terceiro tema era “Abordagens antropológicas e culturais", no qual apresentaram seus trabalhos André Luiz Bertoli (UNL), Bruno Gonçalves Álvaro (UFRJ), Héloïse Hassenforder (U. de Toulouse II), Xavier Storelli (U. de Poiriers) e Vicente Royo Pérez (U. de Valência).

A formação dos grupos de trabalho respeitou as três linhas temáticas expostas acima, sendo os jovens investigadores reunidos e coordenados pelos conferencistas presentes. A proposta inicial do trabalho em grupo era a apresentação e discussão de um artigo escolhido por cada um dos estudantes. Feito isso, passou-se a uma discussão mais abrangente sobre a ampla bibliografia em que estava inserido cada um dos artigos apresentados, a base teórico-metodológica e as diferentes abordagens possíveis sobre as diversas fontes que foram (ou serão) analisadas por cada um dos participantes. Os resultados destas discussões foram apresentados sinteticamente para os outros grupos e seus coordenadores, o que confirmou ainda mais a já percebida diversidade de propostas, evidenciando diversas linhas de investigação e contribuindo para tecer uma visão multifacetada sobre a guerra na Idade Média.

Para concluir, ao longo deste evento foi possível uma aproximação da leitura de historiadores, arqueólogos e filólogos sobre um tema definido, a guerra e a violência guerreira no Medievo, o que possibilitou um contato profundo com diferentes abordagens e análises sobre as fontes documentais existentes, além de uma reflexão sobre a bibliografia, os métodos e as problemáticas apresentadas. Portanto, é necessário destacar a importância deste Atelier Doutoral e sua proposta de um diálogo interdisciplinar entre os medievalistas de diversas áreas do saber científico. 


\section{COMO CITAR ESTE ARTIGO}

\section{Referência electrónica:}

BERTOLI, André Luiz - UNL e IEM recebem o Terceiro Atelier Doutoral da Casa de Velázquez. Medievalista [Em linha]. º9, (Dezembro de 2010). [Consultado dd.mm.aaaa]. Disponível em

http://www2.fcsh.unl.pt/iem/medievalista/MEDIEVALISTA9\bertoli9013.html. ISSN 1646-740X.

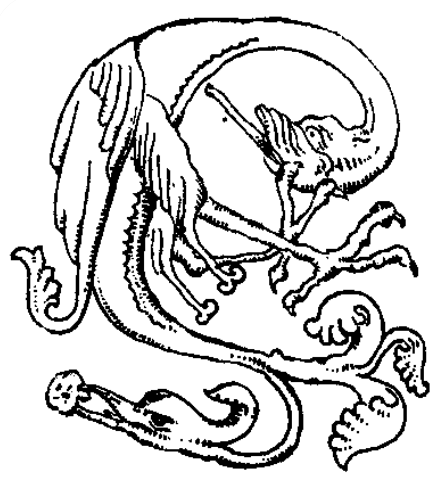

